\title{
Indonesian as Foreign Language: Folklore as Alternative of Aloud Reading Teaching Materials
}

\author{
Rosita Rahma ${ }^{1}$, Ida Widia ${ }^{2}$, Isah Cahyani ${ }^{3}$, Mar'atushshalihah ${ }^{4}$ \\ ${ }^{1234}$ Indonesia University of Education \\ 1rositarahma@upi.edu, 2idawidia@upi.edu, 3isahcayani@upi.edu, \\ 4Maratushalihah@student.upi.edu.
}

\begin{abstract}
The use of literature as BIPA teaching materials can certainly preserve it. Reading legends of literary texts in BIPA learners can also improve not only the ability to read from the texts provided, but also knowledge about Indonesian culture implicit in the legendary story. Reading aloud is one way to help BIPA learners practice Indonesian language skills. This study aims to explain how literary learning in the form of reading legend stories can be an alternative in BIPA learning, especially in reading aloud. This research uses descriptive qualitative research methods. Focus on the question of literary teaching materials such as what can be utilized in BIPA learning. Research techniques in collecting data in the form of observation. The data sources of this research are (1) literary texts in the form of legends, and (2) the learning process of BIPA students. The use of literary learning through legendary stories is linguistic competence, cultural competence, reading, listening and speaking skills. Language competencies that can be achieved include the use of grammar and vocabulary in various legend texts provided.
\end{abstract}

Keywords: Aloud Reading, Folklore Story, Teaching Material

\section{PENDAHULUAN}

Pembelajaran sastra mengacu pada pengajaran kesastraan berbasis teks, baik pembelajaran di jenjang pendidikan formal maupun di lembaga pengajaran Bahasa Indonesia bagi Penutur Asing (BIPA) saat ini. Pengajaran kesastraan berbasis teks diterapkan untuk dapat membantu siswa memahami suatu pesan yang dapat merangsang kemampuan berbahasa siswanya. Seperti pada kemampuan membaca teks sastra legenda, pemelajar BIPA dapat meningkatkan tidak hanya kemampuan membaca dari teks-teks yang disediakan, tetapi juga pengetahuannya mengenai legenda di Indonesia dan budaya di dalam legenda tersebut.

Setiap karya sastra akan terkait dan melibatkan dinamika suatu kehidupan masyarakat, yang memiliki adat dan tradisi tertentu [1]. Dengan membaca cerita legenda, pemelajar BIPA tidak hanya mendapatkan pembelajaran bahasa tetapi juga budaya. Kompetensi budaya yang baik dari pemelajar dapat membuatnya mememahami suatu informasi dan gagasan dengan tepat [2]. Hal tersebut didukung dengan pernyataan bahwa "folklore is an ancient story that has become a special characteristic for every nation with diversity of cultures that embraces the cultural and historical richness of the nation" [3]. Legenda yang berasal dari masyarakat akan memunculkan kekhasan tersendiri dari setiap wilayah. Legenda yang dianggap benarbenar terjadi oleh masyarakat menjadikan pemelajar BIPA dapat menemukan makna dari pembelajaran bahasa melalui legenda. Pemelajar BIPA akan mengetahui bagaimana 
karakteristik masyarakat Indonesia yang beragam sehingga dapat menyesuaikan diri dan beradaptasi dalam lingkungan sekitar.

Pemahaman budaya yang baik oleh seorang pemelajar BIPA akan meningkatkan kepekaan sosial yang ia miliki, akan ada rasa tenggang rasa juga mengurangi kesalahpahaman dalam berkomunikasi dengan lingkungan sekitar. Pembelajaran BIPA tidak dapat terlepas dari pengenalan budaya Indonesia sebab memahami sebuah teks atau wacana bahasa tidak dapat dipisahkan dari budayanya [4]. Nilai budaya lainnya yang dapat diketahui pemelajar BIPA adalah pengetahuan mengenai keanekaragaman hasil budaya seperti destinasi wisata. Cerita asal muasal suatu tempat objek wisata dapat memberikan ruh kelembutan, harmonisasi, dan keunikan yang menyentuh, sehingga pemelajar memahami kesantunan, kebersamaan, kedamaian, dan nilai-nilai etik khas Indonesia lainnya [5]. Nilai-nilai budaya tersebut dapat disampaikan kepada pemelajar BIPA secara inheren bersama dengan penguasaan keterampilan berbahasa, salah satunya dalam pembelajaran membaca.

Terdapat beberapa kesulitan yang dialami oleh pemelajar BIPA saat pembelajaran membaca di kelas. Pemelajar BIPA masih sering tidak dapat membaca dan menyusun katakata dalam kalimat dan sering dipengaruhi oleh bahasa Inggris atau bahasa ibu mereka [6]. Salah satu upaya yang dapat dilakukan untuk mengatasi permasalahan tersebut adalah dengan aktivitas membaca nyaring. Hal tersebut didukung dengan pernyataan "up to present, reading aloud is one of the efficacious and traditional methods to the mother language teaching" [7]. Terdapat beberapa aspek pembelajaran yang bisa didapat oleh pemelajar BIPA melalui membaca nyaring. Membaca nyaring merupakan aktivitas yang menuntut berbagai macam keterampilan [8]. Selain kemampuan membaca, kemampuan berbicara dan menyimak juga dapat dilatih sekaligus melalui kegiatan membaca nyaring. Pemilihan bahan ajar yang tepat juga dapat membantu tujuan pembelajaran membaca nyaring dapat tercapai. Kontribusi bahan ajar dalam pembelajaran di antaranya adalah dapat lebih menarik, kualitas pembelajaran dapat ditingkatkan, dan sikap positif pemelajar pada materi pembelajaran serta proses pembelajaran dapat lebih ditingkatkan [9]. Salah satu bahan ajar bernilai budaya yang dapat dimanfaatkan dalam pembelajaran membaca nyaring adalah cerita legenda [10].

Legenda merupakan produk budaya asli dari daerah tertentu dengan ciri-ciri: (1) memiliki kegunaan bagi pendukung atau kolektifnya, (2) bersifat pralogis, (3) menjadi milik bersama dan tanggung jawab bersama, (4) memiliki sifat polos dan spontan [11]. Teks legenda yang berbeda dengan bahan bacaan lainnya menjadikan pemelajar BIPA bukan hanya berlatih untuk membaca saja, tetapi juga melatih pemelajar untuk dapat mengomunikasikan isi bacaan kepada pendengar, sehingga kisah yang terdapat dalam legenda dapat tersampaikan. Legenda yang merupakan prosa rakyat akan membantu pemelajar BIPA dalam mencapai tujuan pembelajarannya. Teks legenda yang beragam serta memiliki kekhasan dalam setiap cerita akan membantu kemampuan berbahasa pemelajar BIPA disamping juga dapat sebagai alternatif media pengenalan budaya Indonesia [12]. Penemuan kosakata baru, mengetahui pelafalan yang sesuai dengan kaidah dalam suatu kata atau kalimat, serta melatih pemelajar BIPA dalam kefasihan berbahasa Indonesia.

Berkaitan dengan hal tersebut, penelitian ini mempunyai tujuan untuk memaparkan bagaimana pembelajaran sastra berupa cerita legenda dapat menjadi alternatif dalam pembelajaran BIPA khususnya dalam membaca nyaring. Melalui tulisan ringkas ini, diharapkan dapat tergambar bagaimana legenda dapat menjadi alternatif bahan ajar untuk membantu pemelajar BIPA dalam menguasai kemampuan berbahasa khusunya membaca. 


\section{METODE PENELITIAN}

Penelitian ini menggunakan metode penelitian deskriptif kualitatif. Salah satu karakteristik dari jenis penelitian ini adalah pengumpulan data dilakukan dengan cara berinteraksi langsung dengan partisipan di tempat penelitian [13]. Penelitian kualitatif dilakukan karena peneliti ingin mengeksplor fenomena-fenomena yang tidak dapat dikuantifikasikan yang bersifat deskriptif seperti proses suatu langkah kerja, formula suatu resep, pengertian-pengertian tentang suatu konsep yang beragam, karakteristik suatu barang dan jasa, gambar, gaya-gaya, tata cara suatu budaya, model fisik suatu artifak dan lain sebagainya [14]. Hasil penelitian kualitatif ini pun lebih menekankan pada makna dibandingkan generalisasi [15].

Penelitian ini berfokus pada pertanyaan bahan ajar pembelajaran sastra seperti apa yang dapat dimanfaatkan dalam pembelajaran BIPA membaca cerita legenda. Untuk itu, teknik observasi dilakukan dalam pengumpulan data penelitian. Adapun sumber data penelitian ini adalah (1) teks sastra berupa legenda, dan (2) proses belajar mengajar di kelas BIPA tingkat dasar.

Tulisan ini bertujuan untuk menggambarkan kepada pembaca bagaimana pemanfaatan materi sastra teks legenda sebagai alternatif pembelajaran membaca nyaring untuk pembelajaran BIPA. Fokus penelitian ini adalah untuk melihat bagaimana teks legenda dimanfaatkan dalam pembelajaran BIPA dengan tujuan agar siswa dapat memahami teks, menambah wawasan budaya, dan melatif kefasihan dalam membaca.

\section{HASIL DAN PEMBAHASAN}

\subsection{Kondisi Awal Pemelajar BIPA asal Korea Selatan}

Responden dalam penelitian ini merupakan seorang pemelajar BIPA asal Korea Selatan. Responden merupakan pemelajar yang berada pada jenjang BIPA A2 (Tingkat Dasar). Pemelajar memiliki bahasa ibu dan latar belakang budaya yang berbeda. Perbedaan karakter bahasa inilah yang menjadi tantangan tersendiri dalam pembelajaran, terutama berkaitan dengan pelafalan bunyi-bunyi bahasa Indonesia dan bagaimana bahasa itu digunakan dalam konteks penuturan sesuai dengan budaya Indonesia. Akan tetapi, selain perbedaan, responden juga memiliki persamaan yakni sama-sama mengenal cerita legenda suatu tempat. Hal inilah yang mendorong penulis untuk memanfaatkan cerita legenda sebagai bahan ajar dalam membaca nyaring.

\subsection{Praktik Pembelajaran BIPA dengan Memanfaatkan Bahan Ajar Cerita Legenda}

Setelah mengetahui kondisi awal pemelajar BIPA, pembelajar menetapkan cerita legenda sebagai bahan ajar dalam pembelajaran. Meskipun membacakan cerita dan mendongeng memiliki kemiripan konten, keduanya dapat dibedakan dari proses penyampaiannya. Perbedaannya terdapat pada partisipasi penonton. Pada mendongeng penonton difasilitasi untuk mengulangi kalimat yang dibacakan dan diberikan kesempatan untuk menebak jalan cerita dan elemen lainnya pada cerita [16]. Adapun praktik pembelajaran BIPA dengan memanfaatkan bahan ajar cerita legenda dapat diuraikan sebagai berikut.

Pertama, pembelajar menyiapkan bahan ajar yang akan digunakan berupa teks-teks legenda dan menentukan materi yang harus dicapai pada pembelajaran tersebut mengacu pada indikator lulusan Permendikbud nomor 27 tahun 2017. Kedua, pembelajar memberikan modeling membaca nyaring yang baik kepada pemelajar, khususnya untuk mengajarkan cara 
pelafalan atau artikulasi bunyi-bunyi tertentu, intonasi, cara membaca ekspresif dengan mimik yang sesuai khususnya dalam membacakan dongeng. Kegiatan membaca ini sangat berguna untuk pembelajaran bahasa Indonesia bagi penutur asing (BIPA), dan pembelajaran bahasa kedua (bahasa asing, bahasa daerah). Disamping itu, kegiatan membaca nyaring dapat melatih aspek menyimak, dan berbicara dan menambah perbendaharaan leksikal [17]. Dalam pemberian contoh pembelajar menggunakan cerita legenda dengan materi, misalnya nama anggota keluarga. Ketiga, pemelajar yang sudah membacakan cerita legenda bersama pemelajar yang menyimak cerita yang dibacakan akan menyebutkan nama anggota keluarga yang ada dalam cerita tersebut. Kesuksesan pemelajar dalam mencapai standar kompetensi lulusan dapat dilihat dari tingkat kemampuan pemelajar.

Berdasarkan penjelasan sebelumnya, sintak penggunaan bahan ajar membaca nyaring berupa cerita legenda terdiri atas tiga tahap kegiatan, yaitu (1) tahap persiapan, (2) tahap pelaksanaan, dan (3) tahap penilaian. Dengan melaksanakan pembelajaran dengan tahap-tahap yang ada, pemelajar BIPA dapat memperoleh kosa kata baru dalam kalimat sederhana, dan memahami budaya yang terkandung dalam legenda yang dibaca.

Tabel 1. Capaian Kompetensi Berbahasa Pemelajar BIPA Tingkat Dasar dengan Bahan Ajar Legenda

\begin{tabular}{llccl}
\multicolumn{1}{c}{ Kompetensi Berbahasa } & \multicolumn{2}{c}{ Kompetensi Berbahasa } \\
\hline Mampu & Membaca & Menulis & Tata Bahasa & \multicolumn{1}{c}{ Kosakata } \\
mengungkapkan & membaca & - & 1. pronomina & 1. Nama anggota \\
kalimat & nyaring & & 2. kalimat & keluarga \\
ederhana & teks & & sederhana & 2. Ungkapan salam \\
& pendek & 3. kata tanya & 3. Arah \\
& dan & siapa & 4. lokasi \\
& sederhana & & \\
\end{tabular}

Balyaeva, dkk. mengungkapkan bahwa "using folklore by young learners is literary reading contributes to the formation of world views, culture and ethical ideas, the concept of morality. spiritual, and moral development, which are the most appropriate for the characteristics of the psychological and intellectual development of younger students" [18]. Pembelajaran menggunakan bahan ajar Legenda membuat pemelajar berhasil mencapai kompetensi berbahasa pemelajar BIPA tingkat dasar. Hal tersebut ditujukkan dengan pemelajar yang mampu mengenali, dan mengungkapkan kalimat sederhana dengan membaca nyaring sebuah teks legenda pendek yang memiliki komponen ungkapan salam, kataganti nomina, kalimat sederhana, kata tanya siapa, anggota keluarga, arah, dan lokasi. Selain itu, setelah melakukan evaluasi pembelajaran, hasil menunjukkan bahwa pemelajar BIPA merespons kegiatan pembelajaran menggunakan bahan ajar alternatif karya sastra berupa legenda untuk kegiatan membaca nyaring dengan positif. Pemelajar merasa senang membaca cerita legenda saat pembelajaran berlangsung.

Pemelajar merasa mendapatkan pembelajaran budaya dari teks-teks legenda yang mereka bacakan. Selain itu, pemelajar juga merasa lebih mudah memahami materi yang diajarkan, terutama berkaitan dengan pelafalan bunyi-bunyi bahasa dalam bahasa Indonesia. Pembelajaran membaca nyaring akan efektif menggunakan cerita legenda pada pemelajar BIPA tingkat dasar. Meskipun cerita legenda pada penelitian ini tidak diterapkan sebagai sebuah pendekatan seperti yang dilakukan Lee, dkk. dalam membuktikan keberhasilan pendekatan berbasis cerita legenda dengan memaparkan pendapat pemelajar yang menyatakan 
pembelajaran menjadi tidak membosankan, lebih menantang, dan memiliki banyak simulasi yang secara bersamaan menumbuhkan rasa percaya diri pemelajar [19], tetapi cerita legenda sebagai alternatif bahan ajar tetap memberikan dampak yang positif dalam pembelajaran membaca khususnya membaca nyaring pada pemelajar BIPA dasar.

Menerapkan cerita legenda sebagai bahan ajar BIPA juga dapat mengurangi ketidak terjamahan sebuah cerita legenda. Pada penelitian mengenai legenda dari Banjarnegara "The History of Banjarnegara" dan "The Tradition of Cutting Dreadlocks in the Dieng Plateau" [20] yang memanfaatkan cerita legenda sebagai bahan ajar agar legenda tersebut tetap eksis, membuat budaya lokal tidak dilupakan oleh warga pemilik cerita itu sendiri, dan menyebarkannya kepada pemelajar BIPA yang tertarik dengan budaya lokal.

\section{SIMPULAN}

Dari pemaparan sebelumnya, dapat diambil kesimpulan bahwa capaian kompetensi yang dapat diperoleh melalui pemanfaatan pembelajaran sastra melalui membaca cerita legenda BIPA adalah kompetensi kebahasaan dan kompetensi kebudayaan. Keterampilan berbahasa yang dapat dikembangkan meliputi keterampilan membaca, menyimak, dan berbicara. Kompetensi yang dapat dicapai meliputi penggunaan tata bahasa dan kosa kata dalam berbagai teks legenda yang diajarkan, Adapun kompetensi kebahasaan yang dapat pemelajar peroleh dari tata bahasa dan kosakata bergantung pada kemampuan berbahasa pemelajar. Berdasarkan penjelasan tersebut, dapat dikatakan bahwa menggunakan bahan ajar karya sastra berupa legenda sebagai bahan ajar alternatif pada pembelajaran membaca nyaring dapat menunjang pemelajar BIPA dalam mencapai indikator kelulusan pemelajar BIPA tingkat dasar. Penelitian ini baru sampai pada tahap deskriptif, perlu kiranya dilakukan tindak lanjut penelitian berupa pengujian efektivitas penggunaan metode pembelajaran dengan memanfaatkan bahan ajar cerita legenda dalam pembelajaran membaca nyaring. Selain itu, untuk praktisi BIPA juga dapat mengembangkan strategi pembelajaran dengan memanfaatkan karya-karya sastra Indonesia baik klasik atau pun modern lainnya.

\section{REFERENCES}

[1] E. Kosasih, Dasar-dasar Keterampilan Bersastra, Bandung: Yrama Widya, 2012.

[2] R. Rahma, "Praktik Pembelajaran BIPA Tingkat Dasar di Hungaria Melalui Permainan Congklak," in SETALI, Bandung, 2016.

[3] Juni Dikul and Rosliah Kiting, "The Use of Folklore as Educational Entertainment Materials," The International Journal of Social Sciences and Humanities Invention 6, vol. 6, no. 06, pp. 5521-5523, 2019.

[4] M. M. Mussaif, "Keanekaragaman Budaya Menjadi Basis Pembelajaran BIPA," Keanekaragaman Budaya Menjadi Basis Pembelajaran BIPA , vol. 12, p. 169, 2017.

[5] Moh. Muzakka, "Keanekaragaman Budaya Menjadi Basis Pembelajaran BIPA," NUSA, vol. 12, pp. 170-171, 2017.

[6] Hertiki, "PENGAJARAN DAN PEMBELAJARAN BIPA DI PERGURUAN TINGGI POLANDIA," Jurnal Pendidikan Bahasa dan Sastra Indonesia, vol. 6, p. 1, 2017.

[7] L. Huang, "Reading Aloud in the Foreign Language Teaching," Asian Social Science, vol. 6, no. 4, pp. 148-150, 2010.

[8] H. G. Tarigan, Membaca Sebagai Suatu Keterampilan Berbahasa, Bandung: Angkasa Bandung, 2008. 
[9] K. Kurniawan, Belajar dan Pembelajaran Bahasa Indonesia (Panduan untuk Pendidik), Bandung: CV Bangkit Citra Persada, 2012.

[10] I. Widia, "Dongen dan Mendongeng dalam Pembelajaran Sastra di Sekolah Dasar," in Bahasa dan Sastra Indonesia di Tengah Arus Global, Bandung, Jurusan Pendidikan Bahasa dan Sastra FPBS UPI, 2011, p. 110.

[11] S. Endraswara, Metodologi Penelitian Folklore Konsep, Teori, dan Aplikasi, Yogyakarta: PT Buku Kita, 2009.

[12] I. Widia, "Media Pembelajaran Bahasa Indonesia Penutur Asing," in Bahasa dan Sastra Indonesia dalam Perspektif Pendidikan, Bandung, Jurusan Pendidikan Bahasa dan Sastra Indonesia FPBS UPI, 2009, p. 266.

[13] Scumacher dan McMillan, Research in Education, New York: Longman, 2001.

[14] Aan Komariah dan Djam'an Satori, Metode Penelitian Kualitatif, Bandung: Alfabeta, 2011.

[15] Sugiono, Metode Penelitian Kuantitatif Kualitatif dan R\&D, Bandung: Alfabeta, 2012.

[16] Rebecca Isbell, Joseph Sobol, Liane Lindauer, and April Laurence, "The Effects of Storytelling and Story Reading on the Oral Language Complexity and Story Comprehension of Young Children," Early Childhood Education Journal, vol. 32, p. $158,2004$.

[17] E. Iswary, "Strategi Pembelajaran Bahasa Indonesia Secara Terpadu," in International Conference at Hankuk University of Foreign Studies (HUFS), Seoul, 2012.

[18] N. L. S. Z. G. P. BELYAEVA, "Children's folklore as a basis for teaching reading and text analysis," Revista Espacios, vol. Vol. 40 , no. 21, p. 11, 2019.

[19] F. -L. L. d. T. S. L. Jimmy Ho-Man Lee, "FOLKLORE-BASED LEARNING ON THE WEB PEDAGOGY, CASE STUDY, AND EVALUATION," J. EDUCATIONAL COMPUTING RESEARCH, vol. 34, no. 1, pp. 1-27, 2006.

[20] Kundharu Saddhono and Husein Erwinsyah, "Folklore As Local Wisdom for Teaching Materialsin Bipa Program (Indonesian for Foreign Speakers)," International Conference on Social and Political Issues (ICSPI 2016), vol. 2018, no. 10, pp. 444-454, 2018. 